\title{
SEMANTIC AND MORPHOLOGICAL TECHNIQUES OF PSYCHOPATHS IN DARK MATTER YOUTUBE CHANNEL
}

\author{
Indah Maria Ulfa ${ }^{1}$ and Rohmani Nur Indah ${ }^{2}$ \\ Universitas Islam Negeri Maulana Malik Ibrahim ${ }^{1}$, Malang, \\ mariaindah1298@gmail.com \\ Universitas Islam Negeri Maulana Malik Ibrahim ${ }^{1}$, Malang, \\ indah@bsi.uin-malang.ac.id
}

\begin{abstract}
The brain of psychopaths may differ from normal individuals in terms of their cerebral organization of language. Psychopaths have a different way of communicating their ideas within their minds. There is a distinct technique of psychopathic language which can be identified. Therefore, this study examines the kinds of speech technique of psychopaths. It aims at discovering the semantic and morphological techniques used by four psychopaths in the Dark Matter YouTube channel. Methodologically, this study is categorized as descriptive qualitative research. The data were in the form of utterances by four psychopaths in Dark Matter channel posted on October 10, 2019. There were sixteen data in the form of utterances which contained kinds of the speech technique used by psychopaths. The researchers calculated the data by observing, transcribing, describing and analyzing the speech of psychopaths in the Dark Matter channel. Further, the data were classified by using Timor and Weiss (2008) patterns of psychopathic knowledge. The results showed that four psychopathic individuals demonstrated the kinds of the speech technique, which has a distinct pattern using semantic and morphological techniques. Based on semantic technique, all categories found in the data are vocabulary, repetition, figurative language, positive and negative connotations, and anaphora. The result also shows three categories of morphological techniques: nominalization, passivization, and firstperson plural. This study is expected to be a reference for further researcher for analyzing the phenomena of psychopathic language.
\end{abstract}

Keywords: semantic techniques, morphological technique, psychopathic language, psychopaths

\section{INTRODUCTION}

Psychopathy is a personality disorder that is the result of a disruption in the brain system. It genetically makes individuals with a psychopathic personality have a criminal mind. According to Cleckley (1964), a psychopath is a psychological construction that causes a person's behavior to become chronic and antisocial immorality, lack of consciousness, and the ability to lie or deceive without feeling guilt or discomfort. Lack of empathy in psychopaths, make them tend to make deviations of norms or laws in society as a natural behavior. So, they can commit crimes to anyone, anywhere, and anytime.

Recently, in early 2020 the world was shocked by the announcement of a rape case in England. Even this case was labeled as UK's "most prolific rapist" ever in British history. BBC News (2020, January 6) reports that the actor named Reynhard Sinaga, a 36-year-old Indonesian student studying for doctoral degrees 
at Leeds University in the department of human geography. Based on data reported, within two and a half years, from January 1, 2015, to June 2, 2017, there were 48 rape victims with 136 incidents. Reynhard helps drunk people around his flat. He can easily find his target, which is a muscular man, because his flat is surrounded by many clubs. A large number of drunk people make Reynhard easily deceive the victims whether the motive is to give a place to rest or to drink alcohol more. He gives the victims a chemical liquid in the form of GHB (Gamma Hydroxybutyric Acid), which causes the victim to become unconscious when raped by him.

The Guardian (2020, January 6) reports Reynhard is a friendly and nonthreatening person. His voice is soft, smiling face, and lives a simple but capable of all kinds of violence. A close friend described Reynhard as "a sweet man, always happy, likes to smile and laugh". Another friend stated Reynhard as a narcissistic person and often uploaded photos of himself. Therefore, no one would have thought that Reynhard could commit such a cruel act that BBC News (2020, January 6) called "the worst rapist in the UK". Based on his confession in court, he showed no guilt at all. He declared the act as sexual activity based on mutual pleasure rather than rape. According to Simon (2009), psychopaths can be described in an irony, which is when good men and women dream about criminal impulses and curb them, evil men and women act out in reality.

Reynhard 's characteristics illustrate the nature of a psychopath who never feels guilty, rationalizes all his actions, charming, and tends to be narcissistic (Tirto id, 2020, January 7). Hare (1988) describes the character of a psychopath as lacking empathy, guilt, or remorse; shallow emotions; impulsive; egocentric; irresponsible; manipulative; and continuous deviations of social norms. These things are characters that require in-depth analysis from psychologists and psychiatrists to identify whether a person categorized as psychopath. Au (2008) mentions that psychopath process language differently than ordinary people do.

Moreover, identifying a psychopath is very difficult. Their deceptive abilities cause people hardly aware of psychopaths that could endanger them at any time. Robert Hare (1999, as cited in Patrick, 2018) developed a psychopath detection tool in the form of PCL-R (Psychopathy Checklist-Revised). Au (2008) states that "psychopaths prefer an open-ended world, they create ambiguous situations that are potentially dangerous" (Rieber and Vetter, 1994, p.11). The rules that exist in the community are not attractive enough for a psychopath to follow, so they choose to violate them to fulfill their inner satisfaction.

There are some previous studies related to psychopathic language. Endres (2004) and Hancock et al., (2011) reveal psychopathic language by using a detection device in the form of PCL-R. Endres (2004) explained patterns of psychopathic linguistic behavior and the characteristics of psychopathic language. Meanwhile, Hancock et al., (2011) analyzed the part of speech and the semantic meaning of psychopathic language. He found that the characteristics psychopathic language involved using cause and effect descriptors ('because', 'since'), individual needs (food, drink, money), a higher frequency of disfluencies ('uh', 'uhm'), more past tense, and rarely contain indications of social needs (family, religion, etc.).

Based on several previous studies, it is assumed that this study is different from previous studies. It begins with the assumption that, first, psychopaths experience language disorder characterized by a distinct speech technique which can be identified using a linguistic technique. Second, the speech of psychopaths can be analyzed using a linguistic perspective in the form of semantic and 
morphological techniques. The theoretical framework by Timor and Weiss (2008) becomes the main reference in analyzing four psychopathic individuals found in the Dark Matter YouTube channel. Therefore, the purpose of this study is to describe the semantic and morphological techniques used by the psychopathic individuals.

\section{LITERATURE REVIEW}

\section{Psycholinguistics}

Psycholinguistics is a branch of linguistics classified in the external study of language which is a study between psychology and linguistics (Indah \& Abdurrahman, 2008). Carrol (2007) explains that psycholinguistics is part of the emergence of science called cognitive science. Therefore, this interdisciplinary is also related to science, such as neurolinguistics, cognitive psychology, developmental psychology, and speech science. Psycholinguistics researchers focus on the underlying structure of language that is a human biological innate, which comes from the arrangement of the human neurological system (Fernandez \& Cairns, 2011). Psycholinguistics can be interpreted as the science of mental representations and processes involving the language production, comprehension, and storage of spoken and written languages (Warren, 2013). Then, Field (2003) explains that it gives rise to two interconnected goals: the understanding of the process of the underlying system of language and the organization of human thoughts and its patterns.

\section{Language Disorder}

A language disorder is a communication disorder in a person in the form of difficulties in learning and using various forms of language such as speech, writing, or sign. In addition, language disorders can make someone's language abilities different or below the standard language abilities of people of their ages. It is an impairment of the development of language comprehension in spoken, written, and symbol systems in the form of language (phonology, morphology, and syntax), the content of language (semantic system) and the function of language (pragmatic) (ASHA, 1985). Based on that definition of language disorder, the language of psychopathy can be identified in the difference in a person's language ability which in this study will be examined in terms of the content of language (semantic system) and the symbol system in the form of language (morphology).

A normal language skill requires several elements such as the sensing system are complete, the central nervous system is complete, have sufficient mental abilities, have emotional stability, and language equivalent. Therefore, someone that has shortcomings at least one of these elements will have abnormalities in the form of language disorders (Bogshina, 2005 in Indah, 2018). A significant number of psychopaths produced disordered communications. The characteristics of their language disorder can be related to the disorder of schizophrenic individuals (Eisenbarth et al, 1991). Psychopathic individuals showed schizoid features that occurred due to the exhibited signs of frontal lobe dysfunction (Venables and Raine, 1987). In addition, schizophrenic individuals tend to have similarities with psychopathy which may be genetic (Eisenbarth et al., 1991).

\section{Psychopath}


According to Lykken, the term "psychopathic personality" etymologically first appeared in the late 1800s. It embraced a broad group of behavior pathologies suggestive of psychopathology, but unclassifiable in any of the categories of current mental disorder (Patrick, 2018). Psychopaths are capable of being callous, irresponsible, and self-defeating caused by brain damage, insanity, or both (Hare et al., 1999). Merriam Webster dictionary defined psychopath as an egocentric and antisocial personality indicated by an absence of empathy for others, a lack of remorse for one's action, and criminal tendencies. It is estimated that there is $1 \%$ psychopath in the total population and $25 \%$ of inmates in America are indicated by psychopathic personalities. Therefore, Hare (1991, as cited in Patrick, 2018) developed Psychopathy Checklist-Revised (PCL-R), a tool for identifying psychopathic personality which is still used by current experts until today.

\section{Characteristics of Psychopath}

Blair et al. (2005) correlated Conduct Disorder (CD), Antisocial Personality Disorder (ASPD), and Psychopathy. It occurred due to the characteristics of psychopaths that might consist of CD and ASPD traits. People who are surviving either in CD or ASPD are seldom identified as a psychopath. Meanwhile, the identification of psychopath is more complex. The main characteristic of sufferers of Conduct Disorder (CD) is a behavior that deviates from the rights of others or social norms repetitively and persistently. The age of patients at least 18 years old, showing evidence of CD symptoms before the age of 15 years and must not present with antisocial behavior exclusively during the phase of schizophrenia or a manic episode (American Psychiatric Association, 1994).

The brain of psychopaths may differ from normal individuals in terms of their cerebral organization of language. For most people, language function is controlled primarily by the left hemisphere. Evidence showed that the language of psychopaths might differ from that of normal individuals in the way of language processes organized in the cerebral hemispheres. Specifically, language processes in psychopaths may not be as good as normal individuals in terms of left hemisphere resources for processing verbal information (Williamson, 1991).

\section{Language of Psychopaths}

There is something unusual or different about their use of words to normal people. They tend to produce words that are inconsistencies between what they say and what they do (Hare et al., 1988). Their meaning of words might differ from the meaning which normal people produced. Psychopaths are unaware of the real significance of the words they use. The value of sharing in mutuality is beyond their understanding ability (Grant, 1977). It concluded that they fail to feel, they know only the book meaning of words. Their words do not have the same connotations, especially in terms of emotional sense which can be felt by ordinary people.

Psychopaths produced speech that contained a lot of negations (no, not, nothing, etc.), restrictions (concurrently illogical statements), and evaluations (value judgments). Psychopaths are unaware of the real significance of the words they use (Eichler, 1965). Psychopaths have a deep-seated semantic disorder which is called as semantic dementia. There is a complete lack of meaning-related elaborative effective processes. These deficiencies are then "masked" or covered up by their functioning expressive and receptive processes (Cleckley, 1976). 
Psychopaths exhibit a generalized deficit in their ability to interpret and experience emotion (Patrick, 2007).

\section{Semantic Technique}

Semantics is the study of the meanings of words, phrases, sentences, and texts. Timor and Weiss (2008) coined out semantic technique used to identify the speech of psychopaths. According to Timor and Weiss (2008) there are six semantic techniques which can be used to identify the speech of psychopath. It consists of vocabulary, figurative language, negative and positive connotations, anaphora and repetition.

Vocabulary is one of the indications which can show the pattern of someone's language. The choice of words testifies to the speaker's great inner preoccupation with their issue. The figurative language is one aspect in semantic technique which consists of the poetic languages used to dramatize the story. Also, figurative language is intended to convince the listener about the speaker narration. (Katz, 1998, as cited in Timor and Weiss, 2008). A connotation whether the positive or negative one indicates the underlying communicative message that the expression conveys beyond its literal or objective meaning (Leach, 1974, as cited in Timor and Weiss, 2008). Anaphora is the usage of the general term to relate to a word or concept that was mentioned or hinted previously. It enables the subject not to call the things they are talking about by their names but merely hint at them (Richards et al., 1986, as cited in Timor and Weiss, 2008). There are various functions of repetition, whether within the same expression or in synonymous expressions such as emphasizing the expression and reinforcing their validity and unifying the text (Haliday and Hasan, 1976, as cited in Timor and Weiss, 2008).

\section{Morphological Technique}

Morphology is the study of words, including patterns of inflections, derivations, and compositions. Timor and Weiss (2008) coined out semantic technique used to identify the speech of psychopaths. There are four morphological techniques which can be used to identify the speech of psychopath. It consists of first-person plural, second-person singular, passivization, and nominalization

The use of the first-person plural instead of the singular in describing the past act reduces the speaker's own responsibility for the action. This technique is called diffusion of responsibility (Lamb, 1991, as cited in Timor and Weiss, 2008). The use of second-person singular indicated the speaker attempts to describe his act by using second person singular as the subject of his utterances. The use of passive enables the subject to conceal his identity as being the one who is responsible for the situation or it is called agentless passive. It makes the doer unclear, who does participate, and who is responsible for it. The situation was created by itself (Kress and Hodge, 1979, as cited in Timor and Weiss, 2008). Further, the use of nominalization conceals both the object (victim) and the subject (perpetrator) of the offense and neutralizes his responsibility for the action (Kress and Hodge, 1993, as cited in Timor and Weiss, 2008).

\section{METHOD}

The present study intends to identify the patterns of psychopathic language in four psychopathic individuals found in the Dark Matter YouTube channel. This study employs an interpretive paradigm. Rahardjo (2010) explained interpretive 
paradigm is a study to understand the phenomena. The aim of this study is consistent with that definition which is to understand the utterance of four psychopaths. Therefore, the method is qualitative descriptive research for the data of the study is ideographic in the form of utterances produced by four subjects. Qualitative methods rely on text and image data, have unique steps in data analysis, and draw on diverse design (Creswell, 2014, p.232).

The data of this study are ideographic in the form of verbal language (utterances) produced by four psychopaths within their interview sections. The data are obtained from the video of the Dark Matter YouTube channel which is uploaded since October 10 2019. This video is a compilation version of four separate interviews with psychopaths. The duration of the video is 16.54 minutes. At the time researchers watched and downloaded this video, there were more than nine hundred thousand viewers. The video can be accessed at https://www.youtube.com/watch?v=YPYGZztS8IY\&t=5s

In collecting the data, the downloaded video of the Dark Matter YouTube channel is then processed into the transcription. After watching the video several times, the researchers identified the utterances of four persons with psychopaths based on the aims of the study. Finally, the data were sorted and given codes. After the data reduction process, the total number of the utterances analyzed was sixteen. Further, the analysis was done on the utterances produced by four psychopaths in the video. It focused on classifying the utterances based on two problems of study which are the kinds of semantic and morphological techniques used in the utterances.

\section{FINDINGS AND DISCUSSIONS}

\section{The Semantic Techniques Used by The Psychopaths}

Timor and Weiss (2008) concluded that inmates' speech was determined by the denial of guilt and a typical criminal vocabulary style. The use of metaphors or similar figures of speech produced a more specific and extreme oral expression and more persuasive and emotional speech. Also, their language patterns consisted of positive or negative connotations to influence the listener's imagination, hide the doer by using proper noun, and repeat the same word or phrase to convince the listener. After identifying the data, it was found that the subjects in the study have distinct patterns of psychopathic language related to Timor and Weiss model of the speech techniques of psychopaths. The semantic techniques found are classified as vocabulary, repetition, figurative language, connotation, and anaphora.

\section{Vocabulary}

Vocabulary is one of the indications which can show the pattern of someone's language. The choice of words testifies to the speaker's great inner preoccupation with their issue. The content of the expressions points out the speaker's feelings about the situation that they faced. Based on the findings, the vocabularies used by the psychopathic individuals in the present study consist of words which are failure in developing a conscience, typical criminal vocabulary style, and negative self-image of their victims.

Psychopathic individuals tend to use a sensitive word or taboo to describe something or someone. Most of them did not hesitate to mocking or judging others. 
Timor and Weiss (2008) found that psychopaths used a typical criminal vocabulary style. Based on the findings above, vocabulary aspects of psychopathic language placed in the top position of the most often technique appeared in this study (datum 4, 7, 8, 10, 12 and 13). Those characteristics can be seen from the following example:

\footnotetext{
When she grows up to be fourteen-fifteen years old, I will have the perfect sexual mate for sexual purposes, anything else didn't matter it was sex that was it (datum 4).
}

The speaker used words "perfect sexual mate" "sexual purposes". The data above shows Robert's definition and his intention to his stepdaughter. Normal people will view his molestation as a criminal action which means a violation of social norms. However, he sees it as a normal behavior. The terms sex becomes the main topic of his narration in explaining his action. However, when he stated the word "the perfect sexual mate" there was a slower down in his tempo. It seems like he was thinking so hard in rationalizing it. Then, he became fluent and spoke in normal way after he felt he could make sense of it. Also, there is a word "it" which refers to the previous subject. Those words showed his egoism which indicated his failure in developing empathy and conscience (Louth et al., 1998). The features of failure in developing conscience also occurred in the example below.

I had tied his hands with a towel and I was instructed to kill him and I laced the knife that I had in my hand and I couldn't put the knife down I couldn't I couldn't lay down it was just as though there was a force there that held my wrist and I couldn't I couldn't move and as he saw that I couldn't move him (datum 8).

In explaining the utterance above, the speaker looks like thinking so hard. Unlike the other psychopath who speaks confidently, the speaker had a lower tone and does not look like a confident or cold person. The dogma has resulted in her to characterize as an innocent person. It can be seen from the repetition "I couldn't" and the passive "I was instructed". The speaker stated "I couldn't move him". That statement showed her inability doing action with conscience. She felt she was unaware of it as if there was no empathy in her mind when she killed the victims.

Furthermore, the features of vocabularies used by the subject of the present study also consist of typical criminal vocabulary style. Williamson (1991) revealed that psychopaths used excessive jargon, poorly integrated phrases, and had difficulty adhering to one train of thought. It can be seen from datum 10 ("bullshit", "asshole"), datum 12 ("bitch", "the hell"), and datum 13 ("such a pain in the ass"). Those words characterized psychopathic excessive jargon. They tend to create a negative self-image of their victims by blaming and judging them as a bad person.

\section{Repetition}

There are various functions of repetition, whether within the same expression or in synonymous expressions such as emphasizing the expression and reinforcing their validity and unifying the text (Timor and Weis, 2008). Based on the findings above, repetition also placed in the top position which dominates the findings of the pattern of psychopathic language in terms of semantic technique (datum 2, 3, 6, 7, 11 and 16). The example of the repetition is as the following utterance: 
I was the.. I was the one who decided punishment over the children I was the one who spanked the children I was the one who punished the children (datum 2)

In the datum 2 the repetition of "I was the" indicated the speaker's attempt in emphasizing his position as a man who are proper doing the punishment. The repetition used by him functioned as the way of making sense the criminal action done by him. Brites et al. (2014) showed that psychopaths as inmate's subjects have a decreasing ability of language functions due to their jailed conditions. In other words, his spontaneous in explaining the case looked like inequal with their used of words. It seems like his language ability is decreased by showing his failure in making clear sentences. This emphasizing also consisted in datum 15 "it's like..it's like...". Based on that data, it is clear that the pattern of their emphasizing way is by repeating the same group of words in different clauses.

The next datum which is categorized as repetition aspect consisted in datum 3 ("I would, I would"), datum 6 ("anything anything"), datum 7 ("shot shot"), datum 11 ("when I when I). Those data are included in the way of psychopaths in reinforcing their validity. Based on the data, it is clear that the reinforcing way of validity occur by repeating the same words in order or in the same clause. It is different to the emphasizing way which occurs separately.

\section{Figurative language}

This kind of aspects of semantic technique of psychopathic language consists of the poetic languages used to dramatize the story. Also, figurative language is intended to convince the listener about the speaker narration. When the speaker uses a kind of figurative, like metaphors or similes, it makes the utterances more concrete, more extreme, and more emotionally persuasive (Katz, 1998, as cited in Timor and Weiss, 2008).

The finding shows that this feature also often occurs in the speech of psychopaths (datum 1, 10, 13, 15 and 16). It can be seen in the following utterance:

She got me to put in prison, she knows then that a bullshit she pulled the only way to keep from sending her front teeth flying on her asshole is they had me behind this glass (datum $10)$.

The phrase "sending her front teeth flying" is included in the use of hyperbole which dramatize the situation. The speaker tries to make his narration becomes more concrete and more extreme. This category also can be seen in the datum 13 ("pain in the ass") and datum 15 ("with every fiber of my being").

\section{Connotation}

There are two kinds of connotation which are positive and negative form. According to Leach (1974 in Timor and Weiss, 2008) a connotation indicates the latent communicative message that the expression conveys beyond its literal or objective meaning. Based on that definition, it concludes that connotations are connected to the speaker's own perception regarding himself and others.

This study found several data which were categorized as either positive and negative connotation. It differs from the Timor and Weiss's (2008) findings, which the positive and negative connotations occurred in the same amount. Based on the findings above, it can be seen that the quantity of negative connotation more often used by the speaker (datum 3,5 and 11). The subjects used it as a way to conveys their message in negative attitude. The use of connotation is intended by the speaker as a way to manipulate the listener assumption toward the speaker as a person with 
a feeling of humiliation by using negative connotation. Also, the positive connotation is used to attain the speaker's omnipotence (datum 1 and 6).

The negative connotation most often appears in the data. It can be seen in the following utterance:

I didn't care about really, honestly I didn't love the child, I wanted the child for my own purposes, you know and treating them like a person but they were just objects (datum 5).

The speaker used the negative connotation in the words "perfect mate", "just object", Those words describe the speaker negative attitude toward his victim. There is nothing wrong with it. It also shows male domination toward female as the subordinate one. In addition, it indicates his ignorance upon the victim condition. He did not feel he was the one who responsible for the action he had done before.

Next, the positive connotation consisted in the datum 1, and datum 6 . According to Timor and Weiss (2008) the use of positive connotation is an attempt to attain the speaker's positive self-image based on his perception. It can be seen from the words like "punisher", and "decent person". Those words show the speaker great inner preoccupation as the one who can do such killing action. It also represents the worldview of psychopathic individuals which are violent and egocentric. Their fluency, insincerity, and ability to deceive make them have effective use of language (Hare et al., 1988).

\section{Anaphora}

Anaphora is the usage of the general term to relate to a word or concept that was mentioned or hinted previously. It enables the subject not to call the things they are talking about by their names but merely hint at them (Richards et al., 1986, as cited in in Timor and Weiss, 2008). In the present study, the finding shows that anaphora became the rarest aspect used by psychopathic individual based on semantic technique. This aspect is only found in the datum 4 . The speaker changes the word sex to be pronoun "it". Based on the definition above, it is concluded that the use of pronoun "it" is the way of speaker to reduce the listener focus on the criminal action.

Based on the explanation above, the analysis result is summarized in the figure 1, which shows the kinds of semantical pattern of psychopathic individuals in the Dark Matter channel. The figure is the visualization of the analysis results based on the theory by Timor and Weiss (2008).

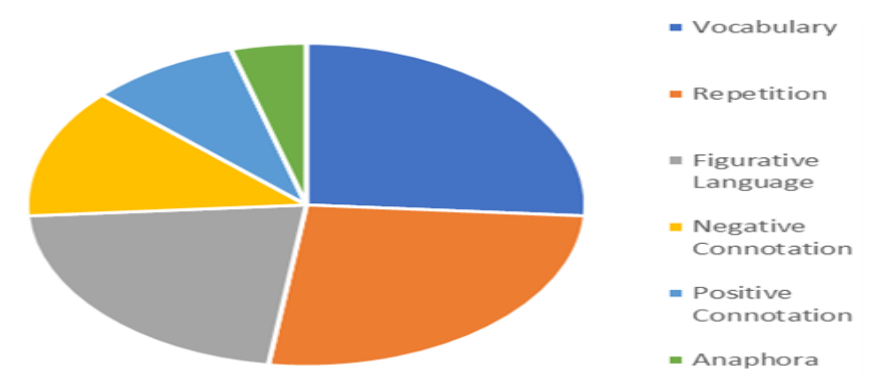

Figure 1. Kinds of semantical technique used by psychopaths

\section{The Morphological Techniques Used by The Psychopaths}


In the second technique of Timor and Weiss (2008) model, they analyzed the morphological techniques. This technique consists of four elements: the use of first-person plural rather than singular form, second person singular rather than plural, passive voice in reducing the focus on subject, and nominal form concealing the doer and the victim. This study found three aspects of morphological techniques: nominalization, passive voice, and first-person plural in the data. The nominalization form becomes the most dominant aspect of morphological techniques found in the findings.

\section{Nominalization}

Nominalization becomes the most often pattern used by the psychopathic individuals in explaining their past criminal action. The use of nominalization conceals both the object (victim) and the subject (perpetrator) of the offense and neutralizes his responsibility for the action (Kress and Hodge, 1993, as cited in Timor and Weiss, 2008). It functions as an attempt to distance the speaker from any connection to the crime. He believes that by using this pattern, it can disconnect himself both from his criminal actions as well as this type of criminal action in the future. So, he does not have responsibility for it. The use of nominalization can be seen from the following:

Oh, how did faith and Liberty die they said they died of gunshot wounds. Yeah the night that I was arrested I had the roses. It didn't have any significance (datum 14).

The data above show how is finally John ready to talk about his daughters. In his mind, he only recognizes his daughters died due to gunshot wounds. He believes it was not him who killed his lovely daughters. He just the one who innocently accused by police because at that time he was together with his daughters. He shows his innocent personality by the words "died of gunshot wounds" and "I was arrested". Based on findings, the use of nominalization in the present study functions as a tool to strengthen the speaker position and the way in concealing the perpetrator in their criminal action. Also, by using this kind of language pattern, the listener will have less focus on the speakers who did wrong.

\section{Passivization}

It also often used by the psychopathic individuals, even though it is not as many as nominalization. The use of passive enables the subject to conceal his identity as being the one who is responsible for the situation or it is called agentless passive. It makes the doer unclear, who does participate, and who is responsible for it. The situation was created by itself (Kress and Hodge, 1979, as cited in Timor and Weiss, 2008). In the present study, this aspect appears in the following example Without saying anything they were gonna fire a shot shot I was noob lucious and that's when the Illinois Steven parent was killed (datum 7).

The data above is uttered by the second psychopathic individual. She was a nineteenth year old Susan Atkins. She developed an obsessive infatuation with the infamous Charles Manson who coming to believe he was the physical return of Christ. He told her of an imminent and apocalyptic reservoir which she immediately believed in him. She was one of the first to volunteer to help Initiate. Then, five innocent people brutally butchered. In this interview, the interviewer asks Atkins when she killed the pregnant actress, Sharon Tate. She shows a frustrated face when she explains her action. The utterance shows how 
psychopathic individual strategy in putting their position as like normal people. They put themselves as a victim of the situation, who is innocently becoming inmates of something that they did not even recognized as a bad action. It also shows that psychopathic individuals have a profound emotion deficit. It is difficult for them to have that kind of empathy. They always use logic in rationalizing their past criminal action.

\section{First-person plural}

Lamb (1991, as cited in Timor and Weiss, 2008) explained that there is a technique used to make a diffusion of responsibility. The use of the first-person plural instead of the singular in describing the past act reduces the speaker's own responsibility for the action. Based on the findings above, this aspect only appears in the datum 5. The speaker hides the actual object which is in the form of her, but instead he used "them". It indicates that the speaker assumes his victim is a group of people not only a person.

Hancock et al. (2011) reveal that psychopaths seem to have little or no conscience. Psychopaths have specific combinations of cognitive, social, and emotional characteristics that differentiate them from the general population. They exhibit a wholly selfish orientation and profound emotional deficit. Psychopaths view the world and others instrumentally as theirs, which can be used as they want. They found that psychopaths used more cause and effect descriptors (e.g., 'because', 'since') as the way to speak more rationally, they focused on individual needs (food, drink, money), and their speech contained a higher frequency of disfluencies ('uh', 'uhm') as the way of planning everything they said, and they used more past tense and less present tense as the way to show their greater psychological detachment from the incident. This model also can be found in the present data. Four psychopathic individuals tend to use 'uhm' while rationalizing their narration. They often describe everything relating their own needs.

There is also a term called semantic dementia by Cleckley (1976) which describes the inability of psychopaths in connecting the true meaning of the words when they are producing the words. It seems like they cannot remember the real meaning which other people know. They have their definition of the words. This kind of inability in processing the meaning of words is categorized as a deep-seated semantic disorder. There is a complete lack of meaning-related elaborative effective processes. Blair (2006) found that psychopaths may claim to understand affective words, but they cannot assure whether it is a real understanding or not. Psychopaths have a perfectly logical process of thinking, but they used the language without really understanding the meaning of what has been said (semantic dementia).

Louth et al. (1998) stated that psychopaths fail to process their utterances in a normal way which clarifies their failure in developing empathy and conscience. Also, they revealed that psychopaths were speaking spontaneously in discussing neutral, negative, and positive emotional topics. It can be seen from the present study, which the first and third psychopathic individual tend to speak spontaneously and confidently. They also do not hesitate in showing their negative attitude toward their victims by blaming and judging them. It is in line with Timor and Weiss (2008) ideas that most inmate male psychopaths tend to attain male power by showing the position of male domination.

Furthermore, talking about their brain, psychopaths have a different way in processing their understanding in their mind. The left hemisphere of psychopathy 
is not functioning normally in terms of language or the source of language processing in the left hemisphere due to its inability (Hare et al., 1988). Specifically, psychopathy may have difficulty in interpreting lexical items in the left hemisphere (Williamson, 1991). The different condition of their left hemisphere makes them often produce words which are not integrated into the meaning. It is like they only know the words but cannot feel the meaning. They tend to produce words that are inconsistencies between what they say and what they do (Hare et al., 1988). It can be found in several data in the present study when the psychopathic individuals express their affectionate feeling, but in fact killed and violated their victims.

The summary of the analysis is presented in figure 2 which shows the kinds of morphological pattern of psychopathic individuals in the Dark Matter channel. The figure is the visualization of the analysis results based on the theory by Timor and Weiss (2008).

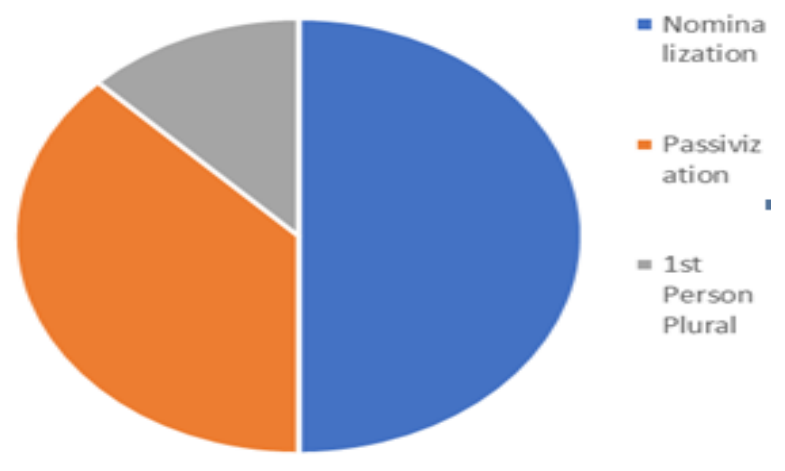

Figure 2. Kinds of morphological technique used by psychopaths

From the discussion above, this study has similarity with the finding of Timor and Weiss (2008). By using semantic technique, the dominant data appeared is the vocabulary aspect. However, the findings of the present study have not only one dominant pattern, but instead, there are two dominant kinds of techniques which are vocabulary and repetition. In answering the second research question, the present study shows that nominalization is the most frequent pattern used by psychopathic individuals in the present study based on the morphological technique. Meanwhile, one aspect of morphological techniques which is second person singular is not found in the speech of four psychopathic individuals.

This study has limitation related to the subject of the study. The further researcher is suggested to conduct psychopathic language research by interviewing the psychopaths directly since the present study only gets the data through video interview on Youtube. The result of this study is limited to the subject in the video which has occurred many years ago. So, the interview with the psychopaths directly will bring information about psychopathic language based on the current situation.

\section{CONCLUSIONS}

Based on semantic technique, the kinds of the speech of psychopaths found are divided into six categories which are vocabulary, repetition, figurative language, positive and negative connotations, and anaphora. The result shows that vocabulary and repetition is the most dominant pattern used by psychopathic 
individuals in this study. Therefore, based on morphological technique, kinds of the speech of psychopaths found are divided into four categories which are nominalization, passivization, first-person plural, and second-person singular. The most dominant pattern of psychopathic language based on the morphological technique is nominalization. However, in this study, there are only three categories of morphological technique used by psychopaths for second-person singular could not be founded.

This study is expected to be a useful insight and extended information on linguistics specifically in psycholinguistics related to psychopathic language. Hopefully, this study gives more information about what a psychopath is, what kinds of the speech of psychopaths using semantic and morphological techniques. Therefore, the next researcher may conduct research using the other techniques in the form of phonology, syntax, or pragmatic. Since this study only analyzes the speech of psychopaths from the video recording, it would be better if the next researcher interviews with psychopathic individuals directly. It will bring clearer and more scientific results on how their real condition based on the current situation.

\section{REFERENCES}

American Speech-Language-Hearing Association. (1985). Clinical supervision in speech-language pathology and audiology. doi:10.1044/policy.PS198500220

American Psychiatric Association. (1994). Diagnostic and statistical manual of mental diseases (DSM-IV). APA.

$\mathrm{Au}, \mathrm{R}$. (2008). Uncovering psychopaths: an automated linguistic approach. Cornell University.

BBC News. (2020, January 6). How the Manchester rapist found his victims. https://www.bbc.com/news/uk-50688975

Blair, J., Mitchell, D., \& Blair, K. (2005). The psychopath: Emotion and the brain. Blackwell Publishing.

Blair, K. S., Richell, R. A., Mitchell, D. G. V., Leonard, A., Morton, J., \& Blair, R. J. R. (2006). They know the words, but not the music: affective and semantic priming in individuals with psychopathy. Biological psychology, 73(2), 114123.

Brites, J. (2016). The language of psychopaths: A systematic review. Aggression and violent behavior, 27, 50-54. DOI:10.1016/j.avb.2016.02.009

Brites, J., Ladera, V., Perea, V., \& García, R. (2014). Verbal functions in psychopathy. International journal of offender therapy and comparative criminology, 59(14), 1536-1549. DOI: 10.1177/0306624X14545608.

Carroll, D. (2007). Psychology of language. Nelson Education.

Cleckley, H. (1964). The mask of sanity: An attempt to clarify some issues about the so-called psychopathic personality. Ravenio Books.

Creswell, J. W. (2014). Research Design: Qualitative, Quantitative, and Mixed Methods Approaches (4th ed.). SAGE publications.

Dark Matter. (2019) 4 Extremely Chilling Interview with Psychopaths. $\mathrm{https}: / / \mathrm{www}$.youtube.com/watch?v=YPYGZztS8IY\&t=5s 
Eichler, M. (1965). The application of verbal behavior analysis to the study of psychological defense mechanisms: Speech patterns associated with sociopathic behavior. The Journal of Nervous and Mental Disease, 141(6), 658-663.

Eisenbarth, H., Alpers, G. W., Conzelmann, A., Jacob, C. P., Weyers, P., \& Pauli, P. (2008). Psychopathic traits in adult ADHD patients. Personality and Individual Differences, 45(6), 468-472.

Endres, J. (2004). The language of the psychopath: characteristics of prisoners' performance in a sentence completion test. Criminal Behaviour and Mental Health, 14(3), 214-226.

Fernández, E. M., \& Cairns, H. S. (2010). Fundamentals of psycholinguistics. John Wiley \& Sons.

Field, J. (2003). Psycholinguistics. Psychology Press

Grant, V. W. (1977). The menacing stranger: A primer on the psychopath. Dabor Science Publications.

Hancock, J. T., Woodworth, M. T., \& Porter, S. (2011). Hungry like the wolf: A word-pattern analysis of the language of psychopaths. Legal and criminological psychology, 18(1), 102-114.

DOI:10.1111/j.2044-8333.2011.02025.x

Hare, R. D., Williamson, S. E., \& Harpur, T. J. (1988). Psychopathy and language. In Biological contributions to crime causation (pp. 68-92). Springer, Dordrecht.

Hare, R. D. (1999). Psychopathy as a risk factor for violence. Psychiatric Quarterly, 70(3), 181-197.

Hare, R. D. (2003). The Hare psychopathy checklist revised. Routledge

Hare, R. D., \& Neumann, C. S. (2006). The PCL-R assessment of psychopathy. Handbook of psychopathy, 58-88.

Indah, R. N. Abdurrahman. 2008. Psikolinguistik, Konsep, \& Isu Umum. UIN Sunan Kalijaga Yogyakarta Malang Press. Malang.

Indah, R. N. (2018). Teori-teori psikolinguistik. repository.uin-malang.ac.id

Jalava, J., Griffiths, S., \& Maraun, M. (2015). The myth of the born criminal: Psychopathy, neurobiology, and the creation of the modern degenerate. University of Toronto Press.

Loevinger, J. (1993). Measurement of personality: True or false. Psychological Inquiry, 4(1), 1-16.

Louth, S. M., Williamson, S., Alpert, M., Pouget, E. R., \& Hare, R. D. (1998). Acoustic distinctions in the speech of male psychopaths. Journal of Psycholinguistic Research, 27(3), 375-384.

Merriam-Webster. (n.d.). Psychopath. In Merriam-Webster.com dictionary. https://www.merriam-webster.com/dictionary/psychopath

Nafiah, U. (2007). A Psycholinguistic study on Expressive Language Disorder of the Autistic Child in Mercury Rising Film. Thesis. UIN Maulana Malik Ibrahim Malang.

Patrick, C. J. (2007). Getting to the Heart of Psychopathy. In H. Hervé \& J. C. Yuille (Eds.), The Psychopath: Theory, Research, and Practice (p. 207-252). Lawrence Erlbaum Associates Publishers.

Patrick, C. J. (Ed.). (2018). Handbook of psychopathy. Guilford Publications.

Raharjo, M. (2010). Desain Penelitian Kualitatif dan Contoh Proses Penelitian Kualitatif. Universitas Islam Negeri Malang. 
http://mudjiarahardjo.uin-malang.ac.id/beranda/185.html?task=view

Rieber, R. W., \& Vetter, H. (1994). The language of the psychopath. Journal of psycholinguistic research, 23(1), 1-28.

Simon, R. I. (2009). Bad men do what good men dream: A forensic psychiatrist illuminates the darker side of human behavior. American Psychiatric Pub.

The Guardian. (2020, January 6). Reynhard Sinaga jailed for life for raping dozens of men in Manchester. https://www.theguardian.com/uknews/2020/jan/06/reynhard-sinaga-jailed-life-drugging-raping-menmanchester

Timor, U., \& Weiss, J. M. (2008). Sociolinguistic and psycholinguistic indications of behavior disorders: analysis of a prisoner's discourse. International journal of offender therapy and comparative criminology, 52(1), 112-126. DOI: 10.1177/0306624X07300268.

Tirto id. (2020, January 7). Reynhard Sinaga, Pemerkosa Paling Jahat di Inggris dari Indonesia. Retrieved from https://tirto.id/reynhard-sinaga-pemerkosapaling-jahat-di-inggris-dari-indonesia-eq97

Venables, P. H., \& Raine, A. (1987). Biological theory. Applying psychology to imprisonment. Theory and practice, 3-28.

Warren, P. (2013). Introducing psycholinguistics. Cambridge University Press.

Williamson, S. (1991). Cohesion and coherence in the speech of psychopathic criminals. Doctoral dissertation, University of British Columbia. 